OPEN ACCESS

Edited by:

Sara Goodacre,

University of Nottingham, UK

Reviewed by:

John Malone,

National Institutes of Health, USA

Eva Garcia-Vazquez,

University of Oviedo, Spain

*Correspondence:

Serge Morand

Centre National de la Recherche

Scientifique-CIRAD, Centre d'Infectiologie Christophe Mérieux du

Laos, Vientiane, Lao PDR

serge.morand@univ-montp2.fr

Specialty section:

This article was submitted to Evolutionary and Population Genetics,

a section of the journal

Frontiers in Ecology and Evolution

Received: 16 May 2015 Accepted: 08 September 2015 Published: 07 October 2015

Citation:

Morand S and Bordes F (2015)

Parasite diversity of disease-bearing rodents of Southeast Asia: habitat determinants and effects on sexual size dimorphism and life-traits.

Front. Ecol. Evol. 3:110. doi: 10.3389/fevo.2015.00110

\section{Parasite diversity of disease-bearing rodents of Southeast Asia: habitat determinants and effects on sexual size dimorphism and life-traits}

\author{
Serge Morand ${ }^{1,2 *}$ and Frédéric Bordes ${ }^{3}$ \\ ${ }^{1}$ Centre National de la Recherche Scientifique-CIRAD AGIRs, Centre d'Infectiologie Christophe Mérieux du Laos Vientiane, \\ Lao PDR, ${ }^{2}$ Department of Helminthology, Faculty of Tropical Medicine, Mahidol University, Bangkok, Thailand, ${ }^{3}$ Centre \\ National de la Recherche Scientifique, Institut des Sciences de l'Evolution, Université de Montpellier, Montpellier, France
}

We investigated a causal chain of relationships between habitat specialization and parasite species richness in rodent communities in Southeast Asia, and the consequences for variation in immune investment (using spleen size), the degree of sexual competition (using testes) and sexual size dimorphism (SSD). We used data gathered on rodents, their habitat specialization and their parasites (macro- and micro-parasites) in Southeast Asian landscapes. The results supported the hypotheses that parasite diversity drives the evolution of host life-traits and sexual selection. Firstly, host habitat specialization explained the variation in parasite species richness. Secondly, high parasite species richness was linked to host immune investment, using the relative spleen size of rodents. Thirdly, according to the potential costs associated with immune investment, the relative spleen size was found to be negatively correlated with the relative size of testes among rodents. Fourthly, a positive relationship between male-biased SSD and parasite species richness was observed supporting the role of parasitism in sexual selection. Finally, the variation in SSD was positively associated with the degree of habitat specialization. Highest values of female-biased SSD were associated with habitat specialization, whereas highest values of male-biased SSD concerned synanthropic or generalist rodent species. These results, also correlative, will help to facilitate selection of the species that should be thoroughly investigated the population level to better understand the selective effects of parasites on rodent life-history and behavior.

Keywords: parasite diversity, life-traits, sexual size dimorphism, spleen, rodents

\section{Introduction}

The search for factors that explain the diversity of parasites has been the goal of numerous studies, whilst the effect of parasite diversity on the evolution of host life-history traits has attracted less, though growing, attention (Kamiya et al., 2014; Morand et al., 2015c). In a recent review, it has been emphasized that ecological and epidemiological theories help to produce testable hypotheses for the determinants of parasite diversity (and/or parasite species richness), whereas, the potential consequences of parasite diversity on the evolution of hosts require investigation with reference to life-history theory (Morand, 2015). 
Host-parasite interactions can be characterized as asymmetrical exploited-exploiter relationships (Morand, 2015). Hosts have to deal with multi-parasitism or co-infection (Bordes and Morand, 2011), with host availability and principally host population size critical for the maintenance of multiple parasite species. Comparative analyses investigating parasite species richness in mammals, and particularly in rodents, have consistently shown that host density (or host population size) and host geographic range are the main determinants explaining parasite richness among host species (Kamiya et al., 2014; Morand, 2015). However, among other potential determinants, rodent behavioral traits (with the exception of host sociality or group size) have received less attention, compared to comparative studies on other mammals such as bats or ungulates, (for interspecific studies see Bordes et al., 2007; for intraspecific studies see Hillegass et al., 2008; Viljoen et al., 2011).

The results of the few comparative studies that have investigated the effects of parasite species richness on the evolutionary ecology of their hosts have stressed four major findings (Morand, 2015): first, that host investment in immune defenses (i.e., immune cells, relative spleen size, immune genes) is related to parasite species richness or infection risk (Nunn et al., 2003; Pilosof et al., 2014, 2015); second, that increased parasite species diversity is linked to an increase in basal metabolism in mammals (Bordes and Morand, 2009) suggesting that increased basal metabolism may be related to an investment in immunity as a consequence of multiple infection; third, multi-parasitism affects life-history traits suggesting the existence of a trade-off between investment in reproduction or organs requiring high energy expenditure, and investment in defense (Bordes et al., 2011); fourth, a positive association between parasite diversity and sexual size dimorphism (SSD) has been observed in mammals, which suggests that multi-parasitism could drive sexual selection (Moore and Wilson, 2002; Krasnov et al., 2012) and ultimately host diversification (Nunn et al., 2004; Morand, 2015).

The goal of this article is to investigate a causal chain of relationships between habitat specialization and parasite diversity in rodent communities in Southeast Asia, and the consequences of this parasite diversity on the variation in the investment in immunity (using spleen size as a proxy), in sexual competition (using testes size as a proxy) and in SSD.

Specifically, we tested the hypotheses of the following framework using a comparative analysis (Figure 1):

(i) Determinants of parasite species richness: the number of hosted parasite species among rodent species should be explained by host availability. Host abundance and breadth of habitat use (or the level of habitat specialization) (Krasnov et al., 2006; Lutz et al., 2015) were included in this analysis. We hypothesized that foraging in a greater diversity of habitats would expose rodents to infection by a greater number and variety of parasites and therefore to higher parasite species richness (a). Moreover, foraging in diverse habitats could increase the number of contacts between rodent species (b) which might increase the chance of sharing a greater number of more generalist parasite species (c) (Bordes et al., 2015);

(ii) Impacts of parasite species richness: hosts must face the detrimental effects of parasite species richness (d), and as susceptibility to parasitism may differ between the sexes, we hypothesized that there would be sex-biased investment in defense (e) (Ponlet et al., 2011; Krasnov et al., 2012). We used the relative spleen size (to body size) as a proxy for the investment in immune defense;

(iii) Parasite mediated trade-offs among life-history traits: trade-offs between investment in costly defenses and other
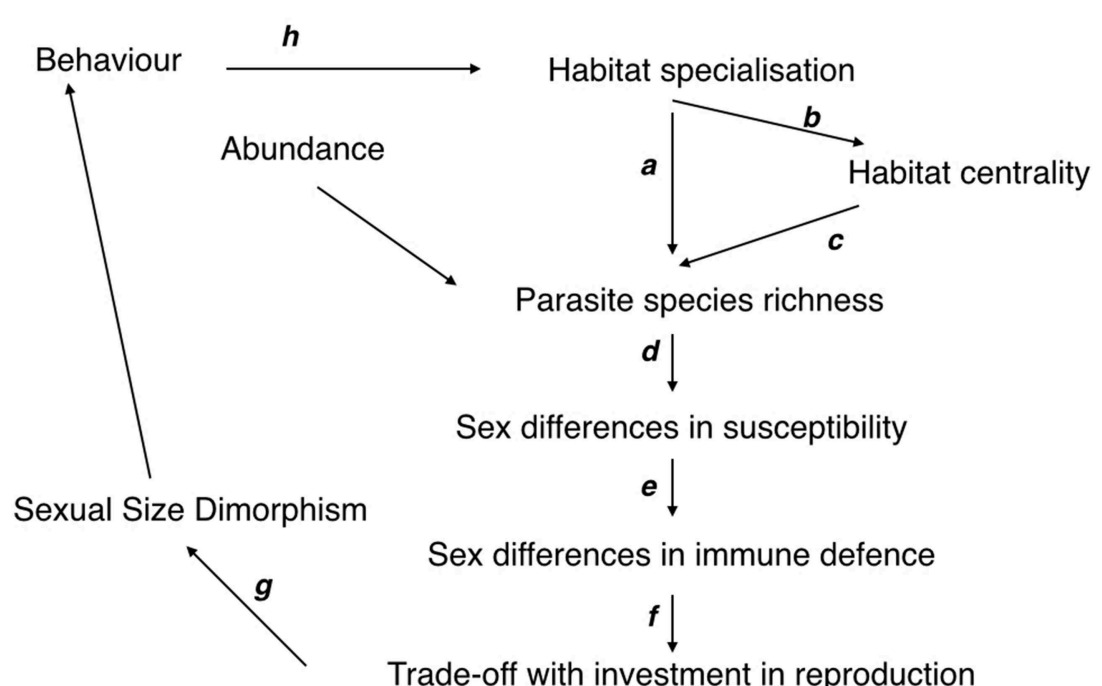

Sex differences in immune defence

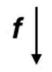

Trade-off with investment in reproduction

and survival

FIGURE 1 | Causal chain of relationships linking habitat specialization, parasite diversity, life-traits and sexual size dimorphism (see Introduction). 
life-traits such as reproduction are likely to occur and may intensify sexual competition and/or the degree of SSD (f) (Moore and Wilson, 2002; Krasnov et al., 2011, 2012). This also implies the existence of a negative relationship between relative spleen mass and relative testes size.

(iv) Intensity of sexual selection and SSD: The intensity of sexual selection and the variation in SSD resulting from the sex-biased impacts of parasite species richness could ultimately affect host behavior and potentially the level of habitat use and specialization in relation to foraging, home range and dispersal. This hypothesis has never been formally tested in rodents, although a significant association between the level of SSD and the specialization in habitat use has been observed in another vertebrate group (with the case of Anolis lizards, Cox et al., 2007).

To test this causal chain of relationships, we used data gathered on rodents and their parasites (macro- and micro-parasites) in Southeast Asian landscapes (see Palmeirim et al., 2014; Blasdell et al., 2015; Bordes et al., 2015; Morand et al., 2015a). We used network analysis to quantify the importance of a given host species in the transmission of parasites (Gómez et al., 2013) and network centrality as a proxy of the relative importance of a rodent species in contributing to parasite sharing. A host species highly central in the network acts as a hub (i.e., a species with a disproportionally large number of interactions) or as a connector (i.e., a species that binds different subgroups of a network) between other central host species (Gómez et al., 2013). We investigated three networks and the centralities of rodent species through the sharing of habitats, the sharing of microparasites (mostly rodent-borne zoonoses) and the sharing of helminth species by rodents (Bordes et al. unpub. data). Investigating parasite species richness at the interspecific level necessitates that host evolutionary history, as depicted by their phylogenetic relationships, is taken into account. Therefore, all analyses were performed using the independent contrasts method.

\section{Materials and Methods}

\section{Ethics Statement}

None of the rodent species investigated are on the CITES list, nor the Red List (IUCN). Animals were treated in accordance with the guidelines of the American Society of Mammalogists, and under European Union legislation (Directive 86/609/EEC). Each trapping campaign was approved by local authorities. Approval notices for trapping and investigation of rodents were given by the Ministry of Health Council of Medical Sciences, National Ethics Committee for Health Research (NHCHR) Lao PDR, number 51/NECHR, and by the Ethical Committee of Mahidol University, Bangkok, Thailand, number 0517.1116/661.

\section{Rodents}

Rodents were trapped in the Thai provinces of Buriram (14.89 $\mathrm{N} ; 103.01 \mathrm{E})$, Loei (17.39 N; 101.77 E) and Nan (19.15 N; 100.83 E), the Laotian provinces of Champasak (15.12 N; 105.80 E) and Luang Prabang (19.62 N; 102.05 E), and the Cambodian provinces of Mondolkiri (12.04 N; 106.68 E) and Preah Sihanouk
(10.71 N; 103.86 E) in 2008 and 2009 within the framework of the CERoPath project (www.ceropath.org). The sampling effort corresponded to a total of 1200 night-traps per trapping session. At each locality, 30 lines of 10 traps were placed during four nights in three different habitats: (1) forests and mature plantations; (2) non-flooded lands or fields (shrubby wasteland, young plantations, orchards); (3) rain-fed lowland paddy rice fields (cultivated floodplain). Villages and isolated houses, which correspond to a fourth habitat category (4), human settlement, were also sampled using cage-traps distributed to residents. The surrounding landscape was described by field observation with a low resolution classification for four main landscape categories: forest, dry fields, rain-fed fields, settlement). Habitat descriptions and the coordinates of trap lines, accompanied by photographs of research sites are available on the CERoPath project web site (www.ceropath.org) (for complete information on trapping sites and rodent identifications see Morand et al., 2015a).

\section{Habitat Specialization}

The degree of specialization exhibited by each rodent species for the four types of habitat was assessed using the Shannon index, estimated using the package spaa (version 0.2.1) and implemented in R. Results were obtained from Morand et al. (2015a) and provided in Table 1.

\section{Helminths and Microparasites}

Rodents trapped were screened for helminth parasites, some of which are known zoonoses (Chaisiri et al., 2010, 2015; Palmeirim et al., 2014). For microparasites, rodent species were investigated for hantaviruses, protists (Toxoplasma gondii, Trypanosoma levisi, and Trypanosoma levansii), Leptospira species (L. borgpetersenii; L. interrogans; L. kirshneri and L. wakefefiedae) and Bartonella sp.(B. coopersplainsensi; $B$. elizabethae; B. queenslandensis; B. rattimassiliensis; B.tribocorum; B. musii and B. phoceensis); (Jittapalapong et al., 2011; Jiyipong et al., 2012; Cosson et al., 2014; Pumhom et al., 2014, 2015). Table 1 summarizes the helminth species richness and microparasite species richness obtained from these published studies.

\section{Host-parasite Ecological Networks}

Rodents are connected through the sharing of helminths, microparasites and habitats. We built bipartite networks (presence/absence) linking each rodent species with their helminths, microparasites, and habitats. The parasite data represented 14 rodent species potentially infected with 15 microparasites and 17 helminth parasites. Bipartite networks where nodes from hosts were found to interact with nodes of pathogens or parasites were then used. We projected these bipartite networks to unipartite networks using the "tnet" package in $\mathrm{R}$ ( $\mathrm{R}$ Development Core Team, 2014). These unipartite networks represented patterns of the relative interactions amongst rodents and humans through the occurrence of shared parasites/pathogens (Bordes et al., unpub. data). 
TABLE 1 | Values of centralities of unipartite networks of shared helminth species, shared rodent-borne diseases, and shared habitat, with values of Shannon index.

\begin{tabular}{|c|c|c|c|c|c|c|c|c|c|}
\hline Species & $N$ & $\begin{array}{c}\text { Body mass } \\
\text { (g) F/M }\end{array}$ & $\begin{array}{l}\text { Spleen } \\
\text { (mg) F/M }\end{array}$ & Testes (mm) & HSR/MSR & $\begin{array}{c}\text { Shannon } \\
\text { index }\end{array}$ & $\begin{array}{l}\text { Centrality } \\
\text { helminths }\end{array}$ & Centrality MS & $\begin{array}{c}\text { Centrality } \\
\text { habititat }\end{array}$ \\
\hline B. indica & 96 & $342 / 354$ & $962 / 907$ & 14 & $9 / 6$ & 0.835 & 0.766 & 0.551 & 0.378 \\
\hline B. savilei & 131 & $159 / 156$ & $441 / 510$ & 12 & $9 / 7$ & 0.834 & 0.811 & 0.734 & 0.488 \\
\hline B. berdmorei & 36 & $173 / 179$ & $495 / 496$ & 16 & $6 / 5$ & 1.244 & 0.524 & 0.398 & 0.515 \\
\hline B. bowersi & 20 & $323 / 296$ & $745 / 746$ & 19 & $3 / 0$ & 0.687 & 0.265 & - & - \\
\hline L. edwardsi & 6 & $393 / 244$ & $277 / 354$ & 22 & $7 / 1$ & 0.637 & 0.531 & 0.082 & 0.067 \\
\hline M. surifer & 130 & $129 / 130$ & $151 / 145$ & 16 & $8 / 6$ & 0.739 & 0.601 & 0.482 & 0.457 \\
\hline M. caroli & 115 & $16 / 13$ & $51 / 54$ & 6 & $6 / 2$ & 0.690 & 0.481 & 0.207 & 0.574 \\
\hline M. cervicolor & 102 & $17 / 16$ & $74 / 75$ & 9 & $8 / 4$ & 0.879 & 0.716 & 0.350 & 0.460 \\
\hline M. cooki & 197 & $21 / 22$ & $106 / 93$ & 9 & $4 / 5$ & 0.891 & 0.362 & 0.421 & 0.882 \\
\hline N. fulvescens & 73 & $63 / 72$ & $86 / 106$ & 14 & $7 / 1$ & 1.073 & 0.605 & 0.088 & 0.526 \\
\hline R. argentiventer & 160 & $92 / 103$ & $217 / 275$ & 11 & $5 / 6$ & 0.613 & 0.440 & 0.531 & 0.398 \\
\hline R. exulans & 509 & $36 / 38$ & $105 / 103$ & 13 & $8 / 8$ & 0.347 & 0.722 & 0.789 & 0.300 \\
\hline R. sakeratensis & 114 & $73 / 77$ & 230/229 & 15 & $8 / 3$ & 0.756 & 0.729 & 0.335 & 0.400 \\
\hline R. tanezumi & 345 & $99 / 111$ & $257 / 280$ & 20 & $14 / 12$ & 1.375 & 1.000 & 1.000 & 0.839 \\
\hline
\end{tabular}

\section{Rodent Centrality}

We used and calculated the eigenvalue centrality (EC) with the "evcent" function from the igraph package in R (R Development Core Team, 2014). EC allows the quantification of the role of a node (i.e., a rodent host species) promoting parasite transmission or occupying various habitats, according to the networks considered. Each host within a host- parasite network plays a different role in pathogen sharing relative to other nodes in the network. With EC, a species (node) with high centrality means that this species is highly connected to other nodes (hosts) and thus is supposed to have a greater potential for transmission of parasites or pathogens to other nodes (hosts). For host-habitat networks, host centrality is linked to the generalist trait of the rodent species, which are able to live or occupy various habitats, allowing interaction with many different species (Bordes et al., unpub. data).

\section{Other Host Traits}

We used the number of individual traps in each locality as a proxy of host abundance as the rodent catching effort was similar in each locality (see the above paragraph "Data on Rodents"). The number of localities where each rodent species was trapped was used as a proxy of host range. The presence and absence of rodents in the investigated localities corresponded well to the distribution range of each species given by the IUCN (http://www.iucnredlist.org, see also www.ceropath.org).

\section{Comparative Analyses}

Comparative analysis using the independent contrasts method allows relationships between species traits to be studied by limiting the false statistical results that are due to phylogenetic pseudo-replications (Felsenstein, 1985). We used phylogenetic information on rodent species based on published studies (see Pagès et al., 2010); (Supplementary Material). We calculated the independent contrasts for each of the investigated variables with the package APE (Paradis et al.,
2004) implemented in $\mathrm{R}$ ( $\mathrm{R}$ Development Core Team, 2014). To confirm the proper standardization of contrasts, we regressed the absolute values of standardized contrasts against their standard deviations. Contrasts then were analyzed using standard multiple regressions, with all intercepts forced through the origin (Garland et al., 1992).

\section{Results}

\section{Host Centrality in Microparasites, Helminths and Habitat Sharing}

Unipartite network centrality values for interactions amongst rodents based on the occurrence of shared helminths and shared microparasites are provided in Table 1. Rattus tanezumi and $B$. savilei showed the highest values of centrality for shared helminths and microparasites. Leopoldamys edwardsi and Niviventer fulvescens showed the lowest values of centrality for shared microparasites, and B. bowersi the lowest for shared helminth species.

Unipartite network centrality values based on shared habitats are also provided in Table 1. Two rodent species showed high values of centrality, $R$. tanezumi and $M$. cookii, whereas $L$. edwardsi showed the lowest values of centrality based on shared habitats.

\section{Comparative Analyses Using Independent Contrasts}

\section{Helminth Species Richness}

The initial model included four variables associated with host availability that may explain parasite infection: host abundance (i.e., the number of individuals trapped), host range (i.e., the number of localities in which the rodent species was trapped), Shannon index (a measure of habitat specialization) and habitat centrality (i.e., the relative importance of sharing habitats with other rodent species). The model best explaining helminth 
species richness included the Shannon index (Table 2). Rodent species living in a high diversity of habitats harbored high helminth parasite species (Figure 2A).

\section{Microparasite Species Richness}

The best model explaining microparasite species richness (rodent-borne diseases), which used the same initial variables as those used for helminth species richness, identified host abundance and the Shannon index as the main explanatory variables of microparasite species richness (Table 2, Figure 2B).

A positive relationship between the residuals in helminth species richness and the residuals in microparasite species richness, both corrected for host abundance and habitat specialization (Shannon index), was also identified (Figure 2C).

\section{Variation in Spleen Size}

The initial model included the variables associated with parasite diversity loads, i.e., helminth species richness and microparasite species richness, and also the variables associated with infection risks: habitat centrality, centrality in sharing helminth parasites and centrality in sharing microparasites.

The models best explaining variation in spleen size in both males and females identified helminth species richness, centrality in habitat sharing and centrality in helminth species sharing (Table 3). It appeared that rodent species, from both sexes, invested in immunity (i.e., spleen size) in relation to the risks of infection through shared habitats and shared helminths, as estimated using network analyses (Figures 3A,B).

\section{Trade-off between Testes Size and Spleen Size}

The initial model included the following variables: body mass (as testes size varies allometrically with body mass) and male spleen mass and the potential associated/confounding variables: helminth species richness, microparasite species richness, host abundance, habitat centrality, centrality in sharing helminth parasites or centrality in sharing microparasite species.

The model best explaining variation in testes size included male body mass, male spleen mass and helminth species richness (Table 4). Variation in testes size was found negatively correlated to variation in spleen mass suggesting the existence of a tradeoff between the investment in immunity and the investment in sexual competition (Figure 4). The increase in testes size was also found associated with helminth species richness. Although, this was non-significant, it was selected by the best model using the AIC criterion (Table 4).

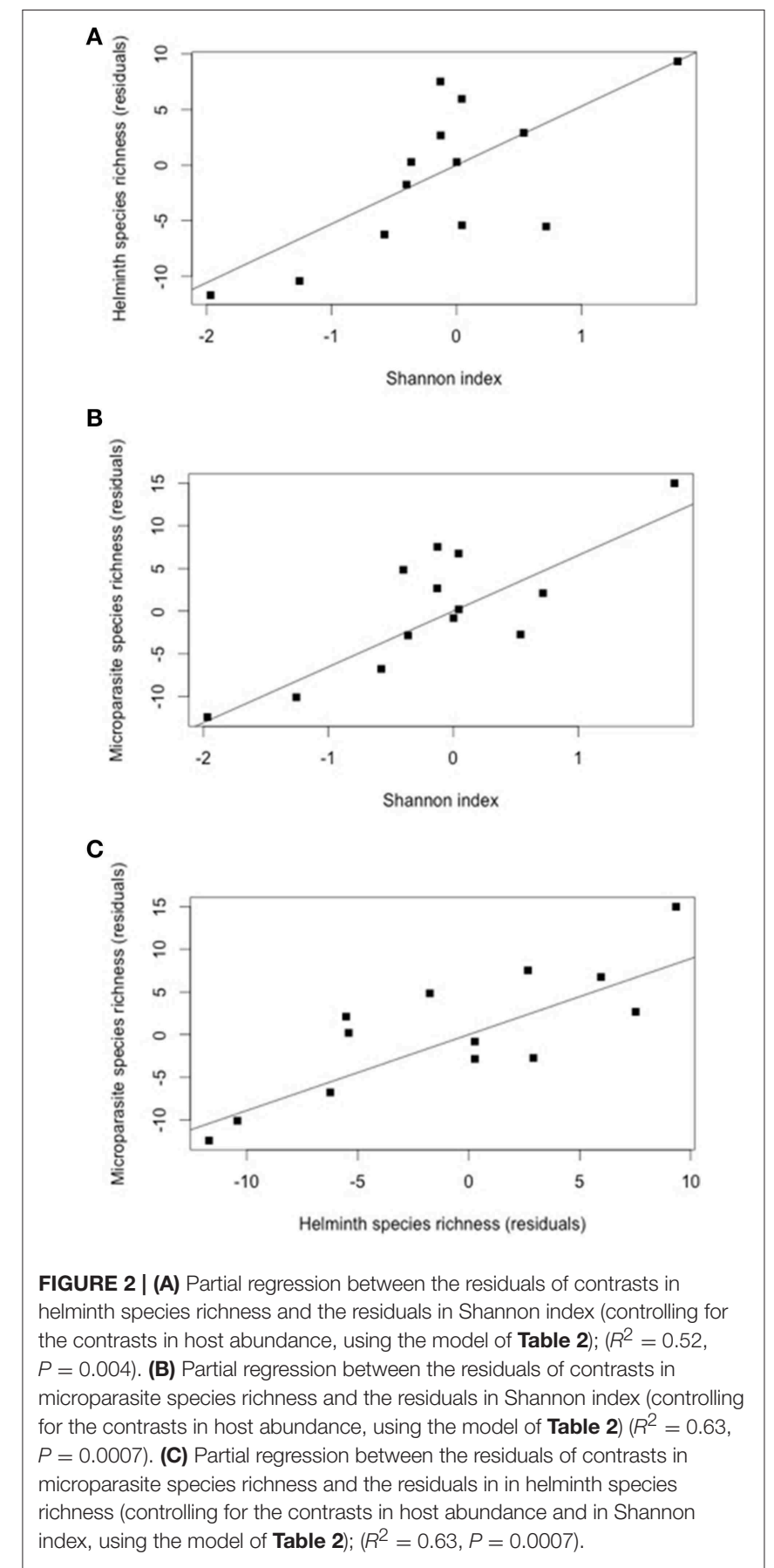

TABLE 2 | Best model explaining helminth species richness and microparasite species richness in Southeast Asian rodents using independent contrasts (initial model with host abundance, host range (number of localities), habitat centrality and Shannon index) using the AIC criteria (with SD =standard deviation of the slope).

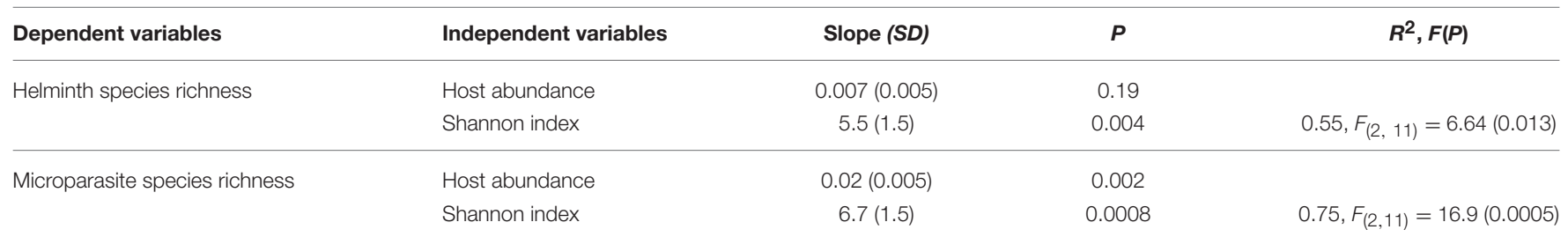




\section{Sexual Size Dimorphism}

Firstly, there were no relationships between variation in SDD and variation in male body mass $(P=0.76)$ or variation in female body mass $(P=0.47)$ using the independent contrast methods.

Secondly, the initial model included the following variables: relative spleen mass, relative testis size, helminth species richness, microparasite species richness, habitat centrality and centrality in sharing helminth parasites or centrality in sharing microparasite species.

The model best explaining variation in SSD identified microparasite species richness (Table 5). Increase in SSD was positively linked with an increase in microparasite species richness (Figure 5).

\section{Habitat Generalist/Specialist}

The initial model included the following variables: host abundance, host range, and host sexual size dimorphism. The model best explaining the level of habitat specialization identified host range and host sexual size dimorphism (Table 6). Increase in SSD was positively linked with the degree of habitat specialization (Figure 6).

\section{Discussion}

The results of our comparative analyses confirmed our hypotheses and the causal chain of relationships between habitat, parasites, life-traits, sexual selection, and SSD (Figure 1).

\section{Determinants of Helminth and Microparasite Species Richness: Host Abundance and Habitat Specialization Matter}

This comparative analysis confirmed the importance of host abundance (as selected by the best model) as a determinant of parasite species richness in rodents (Kamiya et al., 2014; Morand et al., 2015b). However, the importance of host habitat specialization was also found to be an additional determinant. We found that low habitat specialization (as found for habitat generalists) was associated with both high parasite species richness of macroparasites (helminths) and high species richness of microparasites. Rodents showing low levels of habitat specialization to the four types of habitat, using the Shannon index (Morand et al., 2015a), harbored low parasite species richness.
The habitat specialization of Southeast Asian murine rodents is still poorly understood (Adler et al., 1999; Singleton et al., 2003; Wells et al., 2007; Morand et al., 2015a), and most studies have focused on peri-urban or agricultural areas (particularly paddy fields); (Brown et al., 2005; Singleton et al., 2010), or occasionally forested or limestone habitats from the conservation perspective (Wells et al., 2007; Rickart et al., 2011; Latinne et al., 2013, 2015). Here, several rodent species were found to demonstrate high habitat specialization including as $R$. exulans in human

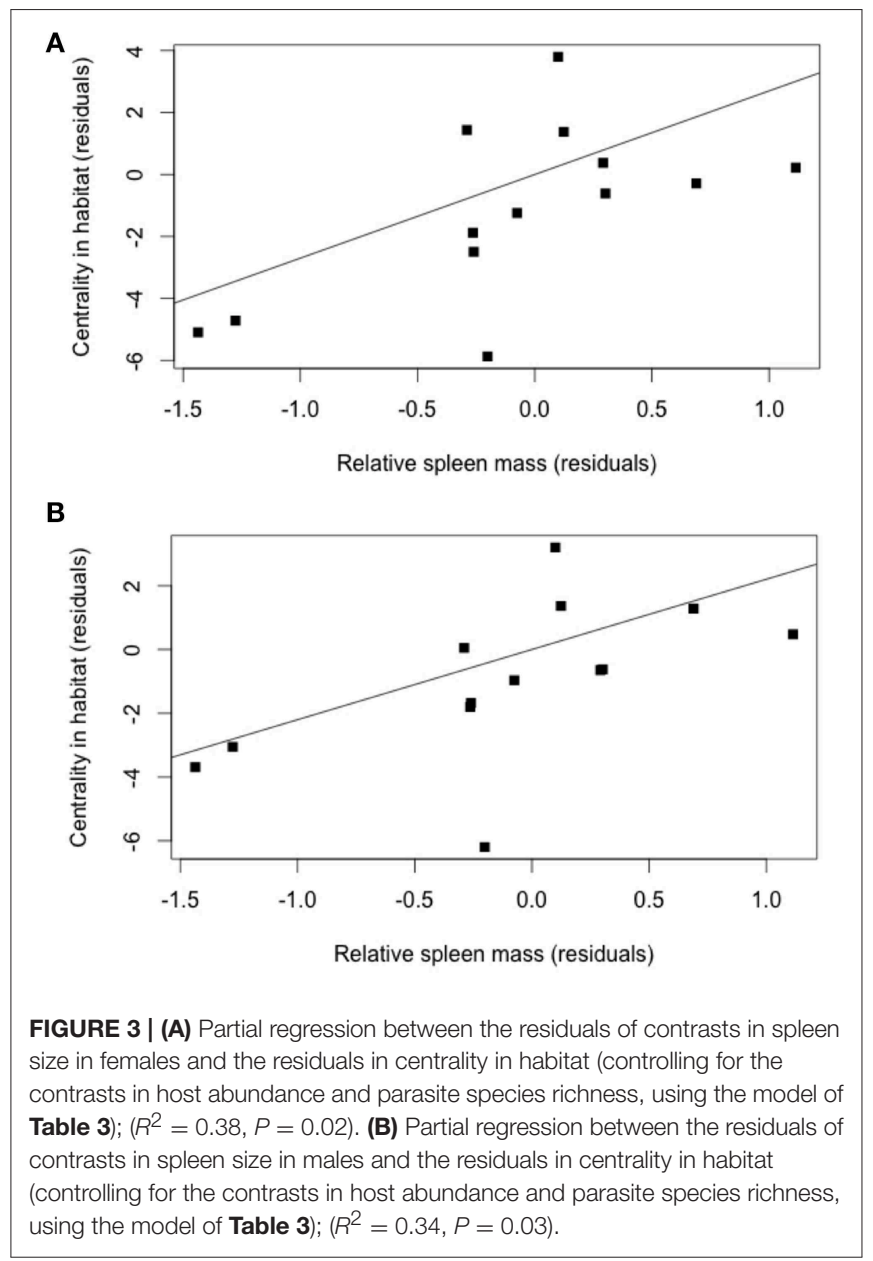

TABLE 3 | Best model explaining the relative spleen mass of female and male rodent species, expressed as ratio to body mass, using independent contrasts; initial model with helminth species richness, microparasite species richness, habitat centrality and centrality in sharing helminth parasites and centrality in sharing microparasites, using the AIC criteria (with $S D=$ standard deviation of the slope).

\begin{tabular}{|c|c|c|c|c|}
\hline Dependent variables & Independent variables & Slope (SD) & $\boldsymbol{P}$ & $R^{2}, F(P)$ \\
\hline \multirow[t]{3}{*}{ Female spleen mass (ratio to female body mass) } & Helminth species richness (residuals) & $-0.9(0.3)$ & 0.02 & \\
\hline & Centrality in habitat sharing & $2.7(1.1)$ & 0.03 & \\
\hline & Centrality in helminth sharing & $10.2(4.4)$ & 0.04 & $0.52, F_{(3,10)}=3.69(0.05)$ \\
\hline Male spleen mass (ratio to male body mass) & Helminth species richness & $-0.8(0.3)$ & 0.03 & \\
\hline
\end{tabular}


TABLE 4 | Best model explaining testes size in rodent species using independent contrasts (initial model with body mass, male spleen mass, helminth species richness, microparasite species richness, host abundance, host body mass, habitat centrality and centrality in sharing helminth parasites or centrality in sharing microparasites) using the AIC criteria (with $S D=$ standard deviation of the slope).

\begin{tabular}{llclc}
\hline $\begin{array}{l}\text { Dependent } \\
\text { variables }\end{array}$ & variables & Slope (SD) & $\boldsymbol{P}$ & $\boldsymbol{R}^{\mathbf{2}}, \boldsymbol{F}(\boldsymbol{P})$ \\
\hline Testes size & Male body mass & $0.08(0.2)$ & 0.0005 & \\
& Male spleen mass & $-0.02(0.007)$ & 0.01 & \\
& $\begin{array}{l}\text { Helminth species } \\
\text { richness }\end{array}$ & $0.5(0.8)$ & 0.09 & $0.81, F_{(3,10)}=14.14$ \\
& & & $(0.0006)$
\end{tabular}

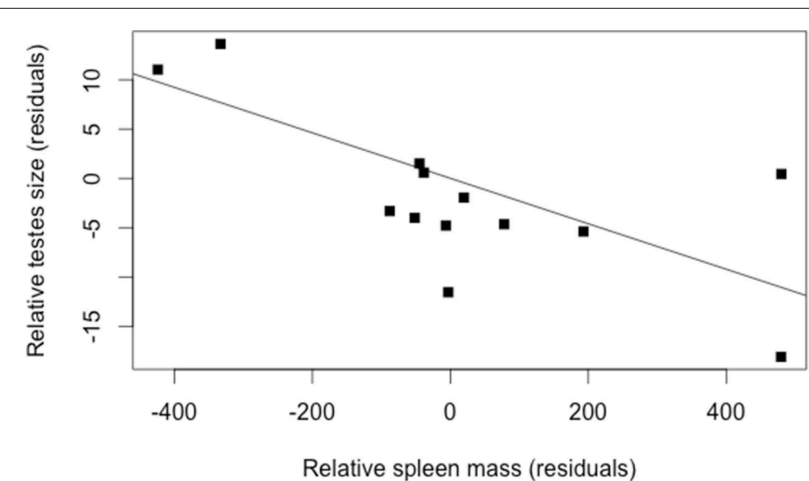

FIGURE 4 | Partial regression between the residuals of contrasts in testes size and the residuals in spleen size in males (controlling for the contrasts in male body mass and parasite species richness, using the model of Table 4); $\left(R^{2}=0.49, P=0.005\right)$.

settlements, $R$. argentiventer and $R$. sakeratensis in paddy rice fields, and L. edwardsi in forests. Other species showed more generalist tendencies such as $R$. tanezumi, which was found in all types of habitat analyzed, including households.

McFarlane et al. (2012) used the terms "synanthropic species," to refer to species ecologically associated with humans, and "generalist" species, to mean ubiquitous species that are able to live in peridomestic environments and/or are able to invade disturbed habitats. McFarlane et al. (2012) showed that the rodent species known to be reservoirs of zoonotic emerging infectious diseases are most likely found in human-modified environments. In this study, the synanthropic species $R$. exulans showed high specialization to settlement habitat, whilst the other synanthropic species $R$. tanezumi showed low specialization. We also observed that the distribution and abundance of generalist rodent species are associated with high diversity of parasites and potential human pathogens. Some of these generalist rodent species are synanthropic and/or invasive species ( $R$. exulans and R. tanezumi); (Morand et al., 2015c).

\section{Impacts of Parasites and Parasite Risk on Spleen Size and Investment in Immunity}

The results also confirmed the hypothesis that high parasite species richness affects the strength of host immune investment (Morand, 2015), potentially due to the high energetic costs
TABLE 5 | Best model explaining sexual size dimorphism in rodent species using independent contrasts (initial model with relative spleen mass, helminth species richness, microparasite species richness, relative testis size and habitat centrality) using the AIC criteria (with $S D=$ standard deviation of the slope).

\begin{tabular}{llccc}
\hline $\begin{array}{l}\text { Dependent } \\
\text { variables }\end{array}$ & $\begin{array}{l}\text { Independent } \\
\text { variables }\end{array}$ & Slope (SD) & $\boldsymbol{P}$ & $\boldsymbol{R}^{\mathbf{2}, \boldsymbol{F}(\boldsymbol{P})}$ \\
\hline $\begin{array}{l}\text { Sexual size } \\
\text { dimorphism in } \\
\text { body mass }\end{array}$ & $\begin{array}{l}\text { Microparasite } \\
\text { species richness }\end{array}$ & $0.02(0.001)$ & 0.01 & $0.41, F_{(1,12)}=8.2$ \\
& & & $(0.01)$
\end{tabular}

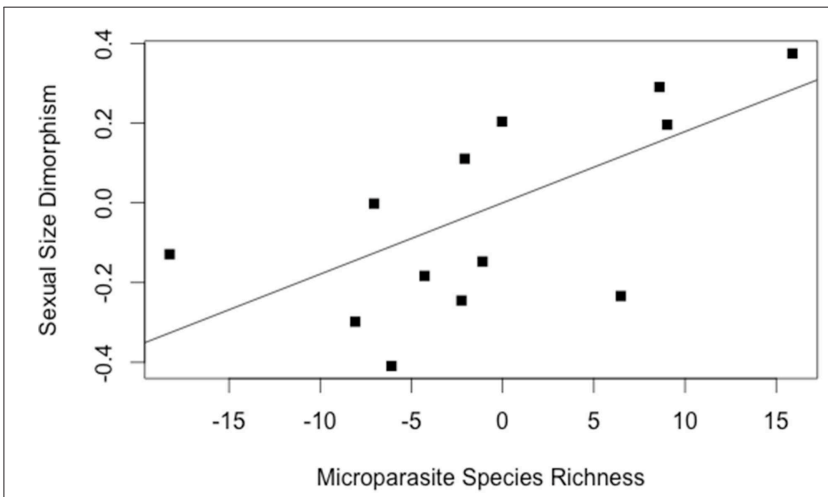

FIGURE 5 | Regression between the contrasts in sexual size dimorphism and the microparasite species richness (from the model of Table 5); $\left(R^{2}=0.41, P=0.01\right)$.

associated with most types of defenses (Brock et al., 2014). We found that both parasite species richness and the risk of being infected, estimated by the central position of a rodent host in habitat sharing, were statistically correlated with the relative variation of spleen size.

Comparative analyses have shown that bird and fish species with high parasite species richness have evolved larger spleen mass compared to their body mass (Morand and Poulin, 2000; Šimková et al., 2008; Ponlet et al., 2011). This was explained as an investment in the production and stockage of lymphocytes in the spleen in order to counteract potential infections (Møller et al., 1998). However, other studies have suggested that spleen mass reflects the host condition and therefore should be negatively related to parasite infection (Corbin et al., 2008; Lutermann and Bennett, 2008; Navarro-Gonzalez et al., 2011). However, these hypotheses are not mutually exclusive.

Here, we found a partial negative correlation between the overall species richness of helminths and the relative spleen mass, which favors the hypothesis that spleen mass reflects host condition. The partial positive relationship observed between the relative spleen mass and habitat centrality, a proxy of the risk of being infected, in contrast supports the hypothesis that spleen mass reflects investment in immune defense.

\section{Parasites and Sexual Selection}

A positive relationship was identified between the testes size and helminth species richness. This suggests that a greater investment in sexual competition occurs in species with high parasite species 
TABLE 6 | Best model explaining habitat specialization (Shannon index) in rodent species using independent contrasts (initial model with host abundance, host range and host sexual size dimorphism) using the AIC criteria (with SD = standard deviation of the slope).

\begin{tabular}{|c|c|c|c|c|}
\hline Dependent variables & Independent variables & Slope (SD) & $\boldsymbol{P}$ & $R^{2}, F(P)$ \\
\hline \multirow[t]{2}{*}{ Habitat specialization (Shannon index) } & Host range (number of localities) & $0.07(0.04)$ & 0.08 & \\
\hline & Host SSD & $2.2(0.73$ & 0.01 & $0.56, F_{(2,11)}=7.02(0.01)$ \\
\hline
\end{tabular}

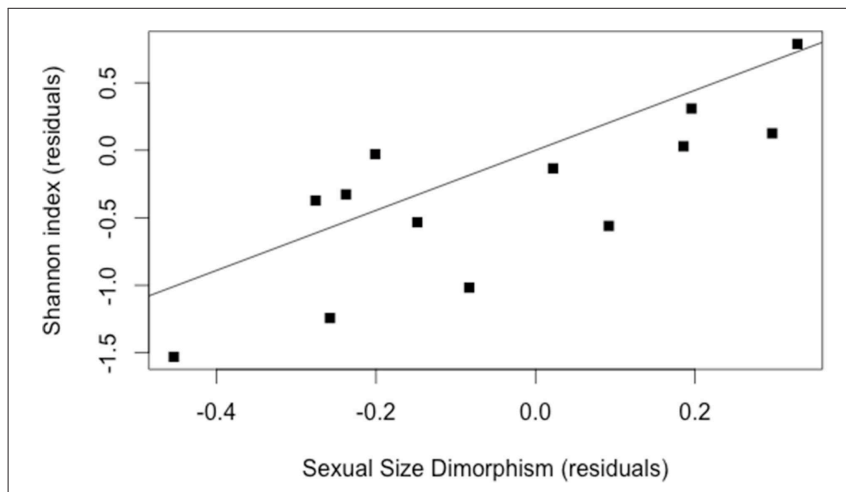

FIGURE 6 | Regression between the residuals in contrasts in habitat specialization (using Shannon index) and residuals in contrasts in sexual size dimorphism (controlling for host range, using the model of Table 6); $\left(R^{2}=0.57, P=0.002\right)$.

richness as proposed by Getty (2002), who emphasized that fit males are able to maintain both good health condition and more parasites than unhealthy males.

\section{Trade-off between Investment in Testes Size and Spleen Size}

Evidence was found for a trade-off between investment in sperm production, using testes size as a proxy (as larger testes produce more sperm than smaller ones, see Parker, 1970), and host immunocompetence using the relative size of the spleen. As mentioned above, larger relative spleens were observed in rodent species exposed to low parasite diversity but with a high risk of being infected, whereas larger relative testes size was observed in rodents exposed to high parasite diversity. As costs associated with investment in immunity can be significant, these results show that relative spleen size is negatively correlated with the relative size of testes.

\section{Sexual Size Dimorphism and Parasites}

Firstly, the results showed no relationship between SSD and body weight in both males and females. The allometric relationship between SSD and body size, also called Rensch's rule, has been documented in a wide range of animals and in many mammalian orders (Fairbairn, 1997; Fairbairn et al., 2007) but not all (for example rodent sciurids, Matějů and Kratochvíl, 2013).

Secondly, the results showed a positive relationship between male-biased SSD and increasing parasite species richness in accordance with the comparative study of Moore and Wilson (2002).
The level of SSD has been explained by the niche variation hypothesis (Dayan and Simberloff, 1994) or by the sexual selection hypothesis (Andersson, 1994; Schulte-Hostedde, 2007). The first hypothesis of niche variation, suggests that an increase in the diversity of food resources leads to an increase of SSD because of sex differences in resources utilization. The lack of data on the diet and the fine ecological niche of the rodents investigated in this study renders this hypothesis difficult to analyze. However, the observed link between testes size and parasite species richness gives some support to the sexual selection hypothesis and particularly to the importance of parasitism as a driving force of the evolution of SSD (Moore and Wilson, 2002; Krasnov et al., 2012). Schulte-Hostedde (2007) suggested that sex differences related to body size and fitness may ultimately lead to different body size optima, where selection pressures may act through male-male competition and female mate choice (Andersson, 1994).

One explanation for female-biased size dimorphism was given by Sullivan and Best (1997), who predicted that productive habitats are characterized by large animals compared to low productive habitats and consequently that the degree of SSD should be larger in populations inhabiting productive habitats. Schulte-Hostedde et al. (2002) hypothesized that large females are at a disadvantage when environmental conditions are extreme because of the energetic costs of reproduction, whereas Levenson (1990) predicted that large females should be favored in severe or seasonal environments. By investigating the geographic variation in SSD of rodents, Schulte-Hostedde (2007) showed that femalebiased SSD declined with increasing annual rainfall and low winter temperatures, indicating that extreme climatic conditions may influence female size and reproductive energetics.

One explanation for male-biased sexual dimorphism is that it has evolved from mating systems, which may influence selection on male body size (Schulte-Hostedde, 2007). However, we found no relationship between the variation in testes size and the level of SSD, suggesting that sperm competition does not affect the evolution of rodent body size.

An additional explanation is that the sex-biased impacts of parasite species richness may affect host behavior such as foraging activities, home range exploration and dispersal. However, few studies have investigated the association between the level of sexual size dimorphism and habitat selection and none of these have been performed in rodents (Cox et al., 2007).

\section{Habitat Specialization: Behavior and Sexual Size Dimorphism}

The level of host habitat specialization was found to be linked to distribution range, which is in accordance with the observation 
that generalist species are locally abundant and have large distribution ranges (Brown, 1995). The results also showed that the variation in SSD is positively associated to habitat specialization. Considering the raw data, the rodent species that showed the highest value of female-biased SSD was the habitat specialist $L$. edwardsi, a species found only in forested habitat. The two species showing the highest values of male-biased SSD were the synanthropic species $R$. argentiventer and $R$. tanezumi. Whilst $R$. argentiventer is found primarily in paddy-rice fields in Southeast Asia, $R$. tanezumi is a generalist species found in all habitats from forests to households (Morand et al., 2015a). Moreover, $R$. argentiventer has shown a geographic expansion associated with human activities in Southeast Asia (Aplin et al., 2003) whilst $R$. tanezumi has colonized urban ecosystems globally (Aplin et al., 2011).

\section{Final Conclusion}

Although, the results of this study are correlative, the trends observed support the hypotheses on the roles of parasite diversity on sexual selection and the evolution of host life-traits. The results suggest that the evolution of SSD in the rodent species investigated is parasite-driven and may have direct consequences for habitat specialization. As much of the ecology of these rodent

\section{References}

Adler, G. H., Mangan, S. A., and Suntsov, V. (1999). Richness, abundance, and habitat relations of rodents in the Lang Bian mountains of southern Viet Nam. J. Mammal. 80, 891-898. doi: 10.2307/1383257

Andersson, M. (1994). Sexual Selection. Princeton, NJ: Princeton University Press.

Aplin, K. P., Chesser, T., and ten Haven, J. (2003). "Evolution biology of the genus Rattus: profile of an archetypal rodent pest," in eds G. R. Singleton, L. A. Hinds, C. J. Krebs, and D. M. Spratt Rats, Mice and People: Rodent Biology and Management (Canberra: Australian Centre for International Agriculture Research), 487-498.

Aplin, K. P., Suzuki, H., Chinen, A. A., Chesser, R. T., Ten Have, J., Donnellan, S. C., et al. (2011). Multiple geographic origins of commensalism and complex dispersal history of black rats. PLoS ONE 6:e26357. doi: 10.1371/journal.pone.0026357

Blasdell, K., Bordes, F., Chaisiri, K., Chaval, Y., Claude, J., Cosson, J.-C., et al. (2015). Progress on research on rodents and rodent-borne zoonoses in Southeast Asia. Wild. Res. 42, 98-107. doi: 10.1071/WR14201

Bordes, F., Blumstein, D. T., and Morand, S. (2007). Rodent sociality and parasite diversity. Biol. Lett. 3, 692-694. doi: 10.1098/rsbl.2007.0393

Bordes, F., Guégan, J. -F., and Morand, S. (2011). Microparasite species richness in rodents is higher at lower latitudes and associated with reduced litter size. Oikos 120, 1889-1896. doi: 10.1111/j.1600-0706.2011.19314.x

Bordes, F., and Morand, S. (2009). Coevolution between helminth diversity and basal immune investment in mammals: cumulative effects of polyparasitism? Parasitol. Res. 106, 33-37. doi: 10.1007/s00436-009-1623-6

Bordes, F., and Morand, S. (2011). The impact of multiple infections on wild animal hosts: a review. Infect. Ecol. Epidemiol. 1. doi: 10.3402/iee.v1i0. 7346

Bordes, F., Morand, S., Pilosof, S., Claude, J., Cosson, J.-F., Chaval, Y., et al. (2015). Habitat fragmentation alters the properties of a host-parasite network: rodents and their helminths in South-East Asia. J. Anim. Ecol. 84, 1253-1263. doi: 10.1111/1365-2656.12368

Brock, P. M., Murdock, C. C., and Martin, L. B. (2014). The history of ecoimmunology and its integration with disease ecology. Integr. Comp. Biol. 54, 353-362. doi: 10.1093/icb/icu046 species is poorly understood (e.g., diet, fine environmental niche, home range, dispersal, longevity, litter size, mating systems, etc.), these findings will help future studies to select the species that should be more thoroughly investigated in order to better understand the selective impacts of parasites on rodent lifehistory and behavior.

\section{Acknowledgments}

This study issued from the French ANR Biodiversity, grant ANR 07 BDIV 012 CERoPath project "Community Ecology of Rodents and their Pathogens in a changing environment" (www.ceropath.org), and the French ANR CP\&ES, grant ANR 11 CPEL 002 BiodivHealthSEA (Local impacts and perceptions of global changes: Biodiversity, health and zoonoses in Southeast Asia). We thank Dr. Kim Blasdell for comments on this manuscript. We also thanks two anonymous referees.

\section{Supplementary Material}

The Supplementary Material for this article can be found online at: http://journal.frontiersin.org/article/10.3389/fevo. 2015.00110
Brown, J. H. (1995). Macroecology. Chicago, IL: University of Chicago Press. Brown, P. B., Phu Tuan, N., Singleton, G. R., Thi Hue, D., Thi Hoa, P., Thi Thu Ha, P., et al. (2005). Population dynamics of Rattus argentiventer, Rattus losea, and Rattus rattus inhabiting a mixed-farming system in the red river delta, Vietnam. Popul. Ecol. 47, 247-256. doi: 10.1007/s10144-005-0228-x

Chaisiri, K., Chaeychomsri, W., Siruntawineti, J., Bordes, F., Herbreteau, V., and Morand, S. (2010). Human-dominated habitats and helminth parasitism in Southeast Asian murids. Parasitol. Res. 107, 931-937. doi: 10.1007/s00436-0101955-2

Chaisiri, K., Siribat, P., Ribas, A., and Morand, S. (2015). Potentially zoonotic helminthiases of murid rodents from the Indo-Chinese peninsula: impact of habitat and the risk of human infection. Vector Borne Zoonotic Dis. 15, 73-85. doi: 10.1089/vbz.2014.1619

Corbin, E., Vicente, J., Martin-Hernando, M. P., Acevedo, P., Perez-Rodriguez, L., and Gortazar, C. (2008). Spleen mass as a measure of immune strength in mammals. Mammal Rev. 38, 108-115. doi: 10.1111/j.1365-2907.2007. 00112.x

Cosson, J. F., Picardeau, M., Mielcarek, M., Tatard, C., Chaval, Y., Suputtamongkol, Y., et al. (2014). Epidemiology of Leptospira transmitted by rodents in southeast Asia. PLoS Negl. Trop. Dis. 8:e2902. doi: 10.1371/journal.pntd.0002902

Cox, R. M., Butler, M. A., and John-Alder, H. B. (2007). "The evolution of sexual size dimorphism in reptiles," in Sex, Size, and Gender Roles. Evolutionary Studies of Sexual Size Dimorphism eds D. J. Fairbairn, W. U. Blanckenhorn, and T. Székely (Oxford: Oxford University Press), 195-204. doi: 10.1093/acprof:oso/9780199208784.003.0005

Dayan, T., and Simberloff, D. (1994). Character displacement, sexual dimorphism, and morphological variation among British and Irish mustelids. Ecology 75, 1063-1073. doi: 10.2307/1939430

Fairbairn, D. J. (1997). Allometry for sexual size dimorphism: pattern and process in the coevolution of body size in males and females. Ann. Rev. Ecol. Syst. 28, 659-687. doi: 10.1146/annurev.ecolsys.28.1.659

Fairbairn, D. J., Blanckenhorn, W. U., and Székely, T. (eds.). (2007). Sex, Size, and Gender Roles. Evolutionary Studies of Sexual Size Dimorphism. Oxford: Oxford University Press.

Felsenstein, J. (1985). Phylogenies and the comparative method. Am. Nat. 125, 1-15. doi: $10.1086 / 284325$ 
Garland, T., Harvey, P., and Ives, A. (1992). Procedures for the analysis of comparative data using phylogenetically independent contrasts. Syst. Biol. 41, 18-32. doi: $10.1093 /$ sysbio/41.1.18

Getty, T. (2002). Signaling health versus parasites. Am. Nat. 159, 363-371. doi: $10.1086 / 338992$

Gómez, J. M., Nunn, C. L., and Verdú, M. (2013). Centrality in primateparasite networks reveals the potential for the transmission of emerging infectious diseases to humans. Proc. Natl. Acad. Sci. U.S.A. 110, 7738-7741. doi: $10.1073 /$ pnas. 1220716110

Hillegass, M., Waterman, J. M., and Roth, J. D (2008). The influence of sex and sociality on parasite loads in an African ground squirrel. Behav. Ecol. 19, 1006-1011. doi: 10.1093/beheco/arn070

Jittapalapong, S., Sarataphan, N., Maruyama, S., Hugot, J. P., Morand, S., and Herbreteau, V. (2011). Toxoplasmosis in rodents: ecological survey and first evidences in Thailand. Vector Borne Zoonotic Dis. 11, 231-237. doi: 10.1089/ vbz.2009.0238

Jiyipong, T., Jittapalapong, S., Morand, S., Raoult, D., and Rolain, J. M. (2012). Prevalence and genetic diversity of Bartonella spp. in small mammals from Southeastern Asia. Appl. Environ. Microbiol. 78, 8463-8466. doi: 10.1128/AEM. 02008-12

Kamiya, T., O’Dwyer, K., Nakagawa, S., and Poulin, R. (2014). What determines species richness of parasitic organisms? A meta-analysis across animal, plant and fungal hosts. Biol. Rev. 89, 123-134. doi: 10.1111/brv.12046

Krasnov, B. R., Bordes, F., Khokhlova, I. S., and Morand, S. (2012). Gender-biased parasitism in small mammals: patterns, mechanisms, consequences. Mammalia 76, 1-13. doi: 10.1515/mammalia-2011-0108

Krasnov, B. R., Stanko, M., Matthee, S., Laudisot, A., Leirs, H., Khokhlova, I. S., et al. (2011). Male hosts drive infracommunity structure of ectoparasites. Oecologia 66, 1099-1110. doi: 10.1007/s00442-011-1950-z

Krasnov, B. R., Stanko, M., Miklisova, D., and Morand, S. (2006). Habitat variation in species composition of flea assemblages on small mammals in central Europe. Ecol. Res. 21, 460-469. doi: 10.1007/s11284-0050142-x

Latinne, A., Meynard, C. N., Herbreteau, V., Waengsothorn, S., Morand, S., and Michaux, J. R. (2015). Influence of past and future climate changes on the distribution of three Southeast Asian murine rodents. J. Biogeogr. 42, 1714-1726. doi: 10.1111/jbi. 12528

Latinne, A., Waengsothorn, S., Rojanadilok, P., Eiamampai, K., Sribuarod, K., and Michaux, J. R. (2013). Diversity and endemism of Murinae rodents in Thai limestone karsts. Syst. Biodiv. 11, 323-344. doi: 10.1080/14772000.2013.818587

Levenson, H. (1990). Sexual size dimorphism in chipmunks. J. Mam. 71, 161-170. doi: $10.2307 / 1382163$

Lutermann, H., and Bennett, N. C. (2008). Strong immune function: a benefit promoting the evolution of sociality? J. Zool. 275, 26-32. doi: 10.1111/j.14697998.2007.00403.x

Lutz, H. L., Hochachka, W. M., Engel, J. I., Bell, J. A., Tkach, V. V., Bates, J. M., et al. (2015). Parasite prevalence corresponds to host life history in a diverse assemblage of Afrotropical birds and haemosporidian parasites. PLoS ONE 10:e0121254. doi: 10.1371/journal.pone.0121254

Matějů, J., and Kratochvíl, L. (2013). Sexual size dimorphism in ground squirrels (Rodentia: Sciuridae: Marmotini) does not correlate with body size and sociality. Front. Zool. 10:27. doi: 10.1186/1742-9994-10-27

McFarlane, R., Sleigh, A., and McMichael, T. (2012). Synanthropy of wild mammals as a determinant of emerging infectious diseases in the Asian-Australasian region. Ecohealth 9, 24-35. doi: 10.1007/s10393-0120763-9

Møller, A. P., Christe, P. H., Erritzoe, J., and Mavarez, A. (1998). Condition, disease and immune defence. Oikos 83, 301-306. doi: 10.2307/3546841

Moore, S. L., and Wilson, K. (2002). Parasites as a viability cost of sexual selection in natural populations of mammals. Science 297, 2015-2018. doi: 10.1126/science. 1074196

Morand, S. (2015). (macro-) Evolutionary ecology of parasite diversity: from determinants of parasite species richness to host diversification. Int. J. Parasitol. Parasites. Wildl. 4, 80-87. doi: 10.1016/j.ijppaw.2015.01.001

Morand, S., Bordes, F., Blasdell, K., Pilosof, S., Cornu, J.-F., Chaisiri, K., et al. (2015a). Assessing the distribution of disease-bearing rodents in humanmodified tropical landscapes. J. Appl. Ecol. 52, 784-794. doi: 10.1111/13652664.12414
Morand, S., Bordes, F., Chen, H.-W., Claude, J., Cosson, J.-F., Galan, M., et al (2015b). Global parasite and Rattus rodent invasions: the consequences for rodent-borne diseases. Integr. Zool. 10, 409-423. doi: 10.1111/1749-4877.12143

Morand, S., Krasnov, B. R., and Littlewood, T. (eds.). (2015c). Parasite Diversity and Diversification: Evolutionary Ecology Meets Phylogenetics. Cambridge: Cambridge University Press.

Morand, S., and Poulin, R. (2000). Nematode parasite species richness and the evolution of spleen size in birds. Can. J. Zool. 78, 1356-1360. doi: 10.1139/z00076

Navarro-Gonzalez, N., Verheyden, H., Hoste, H., Cargnelutti, B., Lourtet, B., Merlet, J., et al. (2011). Diet quality and immunocompetence influence parasite load of roe deer in a fragmented landscape. European J. Wildl. Res. 57, 639-645. doi: 10.1007/s10344-010-0474-x

Nunn, C. L., Altizer, S., Sechrest, W., Jones, K. E., Barton, R. A., and Gittleman, J. L. (2004). Parasites and the evolutionary diversification of primate clades. Am. Nat. 164, S90-S103. doi: 10.1086/424608

Nunn, C. L., Gittleman, J. L., and Antonovics, J. (2003). A comparative study of white blood cell counts and disease risk in carnivores. Proc. R. Soc. Lond. B 270, 347-356. doi: 10.1098/rspb.2002.2249

Pagès, M., Chaval, Y., Herbreteau, V., Waengsothorn, S., Cosson, J.-F., Hugot, J.P., et al. (2010). Revisiting the taxonomy of the Rattini tribe: a phylogeny-based delimitation of species boundaries. BMC Evol. Biol. 10:184. doi: 10.1186/14712148-10-184

Palmeirim, M., Bordes, F., Chaisiri, K., Siribat, P., Ribas, A., and Morand, S. (2014). Helminth parasite species richness in rodents from Southeast Asia: role of host species and habitat. Par. Res. 113, 3713-3726. doi: 10.1007/s00436-0144036-0

Paradis, E., Claude, J., and Strimmer, K. (2004). APE: analyses of phylogenetics and evolution in R language. Bioinformatics 20, 289-290. doi: 10.1093/bioinformatics/btg412

Parker, G. A. (1970). Sperm competition and its evolutionary consequences in insects. Biol. Rev. 45, 525-567. doi: 10.1111/j.1469-185x.1970.tb01176.x

Pilosof, S., Fortuna, M. A., Cosson, J.-F., Galan, M., Kittipong, C., Ribas, A., et al. (2014). Host-parasite network structure is associated with community-level immunogenetic diversity. Nature Comm. 5, 5172. doi: 10.1038/ncomms6172

Pilosof, S., Morand, S., Krasnov, B. R., and Nunn, C. L. (2015). Potential parasite transmission in multi-host networks based on parasite sharing. PLoS ONE 10:e0117909. doi: 10.1371/journal.pone.0117909

Ponlet, N., Chaisiri, K., Claude, J., and Morand, S. (2011). Incorporating parasite systematic in comparative analyses of variation in spleen mass and testes sizes of rodents. Parasitology 138, 1804-1814. doi: 10.1017/S0031182011 00028X

Pumhom, P., Morand, S., Tran, A., Jittapalapong, S., and Desquesnes, M. (2015). Trypanosoma from rodents as potential source of infection in human-shaped landscapes of South-East Asia. Vet. Parasitol. 208, 174-180. doi: 10.1016/j. vetpar.2014.12.027

Pumhom, P., Pognon, D., Yangtara, S., Thaprathorn, N., Milocco, C. Douangboupha, B., et al. (2014). Molecular prevalence of Trypanosoma spp. in wild rodents of Southeast Asia: influence of human settlement habitat. Epidemiol. Infect. 142, 1221-1230. doi: 10.1017/S0950268813002161

R Development Core Team (2014) R: A language and Environment for Statistical Computing (edited by R.F.f.S. Computing). Vienna: R Foundation for Statistical Computing.

Rickart, E. A., Balete, D. S., Rowe, R. J., and Heaney, L. R. (2011). Mammals of the northern Philippines: tolerance for habitat disturbance and resistance to invasive species in an endemic fauna. Div. Dist. 17, 530-541. doi: 10.1111/j.1472-4642.2011.00758.x

Schulte-Hostedde, A. I. (2007). "Sexual Size Dimorphism in rodents", in Rodent Societies: An Ecological and Evolutionary Perspective eds J. O. Wolff and P. W. Sherman (Chicago, IL: The University of Chicago Press), 115-138.

Schulte-Hostedde, A. I., Millar, J. S., and Gibbs, H. L. (2002). Femalebiased sexual size dimorphism in the yellow-pine chipmunk (Tamias amoenus): Sex specific patterns of annual reproductive success and survival. Evolution 56, 2519-2529. doi: 10.1111/j.0014-3820.2002. tb00176.x

Šimková, A., Lafond, T., Ondracková, M., Jurajda, P., Ottová, E., and Morand, S. (2008). Parasitism, life history traits and immune defence in cyprinid fish from Central Europe. BMC Evol. Biol. 8:29. doi: 10.1186/1471-2148-8-29 
Singleton, G. R., Belmain, S., Brown, P. R., Aplin, K., and Htwe, N. M. (2010). Impacts of rodent outbreaks on food security in Asia. Wildl. Res. 37, 355-359. doi: 10.1071/WR10084

Singleton, G. R., Hinds, L. A., Krebs, C. J., and Spratt, D. M. (2003). Rats, Mice and People: Rodent Biology and Management. Canberra: ACIAR.

Sullivan, R. M., and Best, T. L. (1997). Effects of environment on phenotypic variation and sexual dimorphism in Dipodomys simulans (Rodentia: Heteromyidae). J. Mammal. 78, 798-810. doi: 10.2307/1382937

Viljoen, H., Bennett, N. C., Ueckermann, E. A., and Lutermann, H. (2011). The role of host traits, season and group size on parasite burdens in a cooperative mammal. PLoS ONE 6:e27003. doi: 10.1371/journal.pone.0027003

Wells, K., Kalko, E. K. V., Lakim, M. B., and Pfeiffer, M. (2007). Effects of rain forest logging on species richness and assemblage composition of small mammals in Southeast Asia. J. Biogeog. 34, 1087-1099. doi: 10.1111/j.13652699.2006.01677.x

Conflict of Interest Statement: The authors declare that the research was conducted in the absence of any commercial or financial relationships that could be construed as a potential conflict of interest.

Copyright (๑) 2015 Morand and Bordes. This is an open-access article distributed under the terms of the Creative Commons Attribution License (CC BY). The use, distribution or reproduction in other forums is permitted, provided the original author(s) or licensor are credited and that the original publication in this journal is cited, in accordance with accepted academic practice. No use, distribution or reproduction is permitted which does not comply with these terms. 